\title{
Phenomenology and Rigid Dualisms: Joachim Renn's Critique of Alfred Schutz
}

\author{
MICHAEL D. BARBER \\ Department of Philosophy, St. Louis University, 3800 Lindell Blvd., PO Box 56907, \\ St. Louis, MO 63156-0907, USA \\ (E-mail: barbermd@slu.edu)
}

\section{Erratum to: Human Studies 29: 21-32 DOI: $10.1007 / \mathrm{s} 10746-005-9013-2$}

This is the amended version of the article by the same name that originally was published in Human Studies 29/1. That version did not include the page references to the article by Joachim Renn, in the same issue, to which it was responding. This amended version corrects those omissions. The online version of the original article can be found at http://www.dx.doi.org/10.1007/s10746-005-9013-2.

\begin{abstract}
Joachim Renn argues that Schutz fails to integrate two fundamental strands in his work: phenomenology and pragmatism. Gaps between separated consciousnesses block synchronization and access to others, and objective symbol schemes, absorbed within the egological outlook, cannot bridge these gaps. Renn, however, construes phenomenology as practicing a solipsistic withdrawal of a self cut off from its environs, denies that contents correlative to individual intentional acts can be objective and common, and overlooks the intricacies of Schutz's descriptive methodology. Furthermore, for Renn, Schutz's distinctions between inner and outer time and ego and alter congeal into hardened dualisms. Renn expects more than Schutz's methodology can deliver, but correctly points to problems of the social world that need to be addressed by several philosophical strategies, including pragmatism and Schutzian phenomenology.
\end{abstract}

Key words: consciousness, meaning, phenomenology, pragmatism, Schutz, signs, temporality

In "Appresentation and Simultaneity: Alfred Schutz on Communication between Phenomenology and Pragmatics," a paper presented at the Alfred Schutz Centennial Conference at the University of Konstanz in May 1999, Joachim Renn argues that Schutz's account of communication 
fails to integrate the two fundamental perspectives underlying his account of the Lebenswelt: phenomenology and pragmatism (Renn, 2006). In this paper, I hope to present Renn's critique, which is one of several efforts by such thinkers as Welz (1996) and Habermas (1988) that rely on the pragmatic tradition to highlight the difficulties of Schutz's attempt to come to terms with that same tradition in his own phenomenology. In the second part of the paper, I will assess Renn's critique and, in a brief third section, discuss prospects for a rapprochement between Schutz's phenomenology and pragmatism.

\section{The Pragmatic Critique of Schutz's Phenomenology}

Renn (2006: 4) shows how Schutz transfers Husserl's approach from constitution to a conceptualization of action portrayed as the result of a series of internal polythetic acts and, at the same time, construes action in terms of act types, which are provided by socially transmitted, objective interpretation schemes. For Renn, though, the different methodologies at play here are inconsistent. On the one hand, Schutz still clings to the vestiges of Husserl's transcendental consciousness, even though he rejects the idea that the intersubjectivity of meaning is nothing more than a "mere transcendental implication of subjectivity" - but it must be noted that Schutz's critique of Husserl's Fifth Cartesian Meditation is much more specific and complex than Renn here implies. On the other hand, Schutz endorses "a pragmatic notion of an interactive constitution of sense" that is simply taken for granted (Renn, 2006: 5-6).

In the second major section and heart of his paper, "Two Methods and Two Theories of Communication," Renn (2006: 6) continues this line of critique by asserting that Schutz embraces both a synchronization account of communication that is phenomenological as well as a more pragmatic, linguistic approach derived from Husserl's theory of appresentation. In the end, though, Schutz finally attempts to resolve the tensions between these views by reverting to "egological subjective constitution."

The synchronization account of communication runs into two problems. The first has to do with Schutz's idea of "growing older together," exemplified when two persons together perceive an event in outer time, such as the flight of bird, and this event is simultaneous with their perceiving of it - a perception that pertains to the inner time of each. According to Schutz (1962: 317, 1967: 103-104, 1974: 144), the two fluxes of inner time, mine and the other's, are synchronous with the event in outer time and, therewith, one with the other. But Renn (2006) asks, what is the criterion of identity which allows ego to identify the outer time of 
ego with outer time of alter ego? The only warrant Schutz seems to give for this identity is a "disturbingly naturalistic interpretation of linguistic performances and action and events in the causal relation of the outward empirical world" (Renn, 2006: 7). This is especially problematic since in the very place in which Schutz (1967: 103, 1974: 144) develops the simultaneity of the two streams of consciousness in relation to an event in outer time, he also is "insisting on the radical difference between outer time and durée" (Renn, 2006: 17). As a result, there is a "radical difference" between the constructed inner time the subject projects and the outward sequence of observable action.

The second problem with the synchronization argument has to do with the asymmetric access that each ego has to the other's experience. According to Schutz (1967: 102, 1974: 143), ego must attend to its own experiences reflectively, insofar as a reflective act always supervenes upon the conscious stream that preceded it, if only momentarily, but one can observe alter's experiences "as they actually take place," even though these experiences are pre-phenomenal and undifferentiated for alter, who can only apprehend his or her experiences after they have passed. Renn (2006: 8) finds Schutz inconsistent at this point insofar as he states both that ego has "certain" access to alter's stream (and alter's to ego's) and that ego's understanding of alter's ego still remains confined to ego's understanding. This "rigid" difference between ego's understanding of alter and alter's self-understanding reappears when Schutz discusses the fringes of meaning resulting from the different biographies and schemes of relevance that add idiosyncratic connotations to general, objective meanings. Certainly, the understanding by ego of alter ego falls far short of the "epistemic certainty" that ego's better access to alter's temporal stream seems to afford.

One way out of this mutual enclosure within streams of consciousness is to focus instead on the pregiven intersubjectivity of symbolic structures, especially, socially transmitted types and interpretation schemes, and Schutz (1962: 323) adopts exactly this strategy in appropriating Husserl's notion of appresentation, according to which signs are coordinated with objects prior to and independently of their deployment by any conscious subject. However, when Schutz (1962: 294-300) examines Husserlian appresentation - and Renn (2006: 9-10) here refers to section two of Schutz's essay, "Symbol, Reality, and Society" - there are only three relata: sign, meaning, and subject, as opposed to the four relata that would have been called for if he had been consistent with his earlier discussion of synchronization: sign, meaning, ego, and alter. Renn (2006: 9) concludes that "the account of language turns back to the monological model of subjective sense constitution, which is the heritage of Husserl's egological theory of meaning." 
In fact, it is the pregiven appresentational schemes, presupposed by temporally co-present consciousnesses, which overcome the gap between these consciousnesses to which Schutz's phenomenology leads (Renn 2006: 10). In addition, Schutz's work lacks a clear concept of "genuine interactive symbol generalization," which for Renn (2006: 10) presupposes "the regularity of cooperative action as the basis of context-transcending symbolization," that is, the kind of interactive constitution of linguistic meaning pervasive in the works of Mead and Dewey. Renn (2006: 10) admits that Schutz's account of intersubjective appresentational schemes may be adequate for his purposes, but at least he should have developed an account of intersubjective sense constitution elsewhere. Further, when it comes to discussions of this pragmatic constitution of meaning, one must refer to linguistic and social rules of performance and not just to the representation of intentional objects. Rules of action and speaking cannot be reduced to cognitive concepts that actors and speakers "have in mind," although insofar as Schutz did envision typifications as including role-taking (Renn, 2006: 11), he did make overtures toward a pragmatic understanding of action. Schutz, though, treats neither the problem of social order nor the conditions of the internalization of meaning that for pragmatists play a central role in the social constitution of the sense-constituting subject itself (Renn, 2006: 11-12).

In the concluding sections of his paper, Renn (2006: 13) speculates that Schutz resisted any incorporation of such pragmatic themes since he mistakenly conceived pragmatism, taking Mead's version as representative, in behavioristic terms. It is as though Schutz conceived intersubjective influence in terms of "the rigid intrusion of social convention into the innermost self-relation of the interpreting subject," leaving the ego a passive resonator of conventional intersubjective sense. Nevertheless, Schutz's concerns about the value of subjective freedom over against objectivism have merit. Along these lines, Renn (2006: 15) suggests as a replacement for behavioristic pragmatism a type of pragmatism that would involve a "communicative constitution of the mundane ego" to be realized in social and linguistic practice. While Renn's proposal here seems to converge with the views of Habermas, Renn (2006: 16) is also wary of Habermas's selective recognition of subjective sense constitution, and he suggests that Schutz's insights will continue to be of value when it comes to participants in "concrete encounters, which determine particular meaning aspects with regard to contextual circumstances." 


\section{A Critique of the Critique}

It is of first importance to be clear about Schutz's methodology in examining intersubjective relationships. In his discussion of Husserl's constitution of the other in the Fifth Cartesian Meditation, Schutz (1966: 58) begins by affirming with Husserl (1960: 91) that even after the phenomenological reduction, the world, including the other, is not experienced as one's private synthetic product but as an intersubjective world whose objects are accessible to everyone. In other words, the phenomenological reduction does not involve transmigrating to another ontological realm totally distinct from the everyday, social world or denying that social world or making it disappear, but rather turning to it reflectively in such a manner that the contents of one's reflection are still marked by all the social dimensions in which one had just previously been unreflectively living (Husserl, 1960: 19-20; Schutz, 1962: 258). The problem for Schutz (1966: 60, 65-66, 69, 76, 83) comes when Husserl implements the second epoché, in which he artificially suspends "the hidden intentionality of the founding mundane intersubjectivity" even though at places he covertly makes use of it. In this second epoché leading to the primordial sphere, Husserl seeks to abstract from one's experience of the world as a "world for everyone"; and, for Schutz, this attempt to constitute the other that begins with second epoché consists in a "desperate attempt to escape the appearance of solipsism," which, paradoxically, gives rise to just that appearance (Schutz, 1966: 57, 83). Moreover, in subsequent stages of this constitution processes (e.g. the analogical apprehension of an other's living body, the appresentation of the other's primordial world, and the empathic transfer of localizations), Schutz (1966: 63-64, 68, 71-72, 76) contends that one cannot proceed from the uniqueness of one's primordial sphere to the other's. In the end, one ends up constituting the other just for oneself and not for all other transcendental egos. Consequently, Schutz (1966: 82) concludes, "It is to be surmised that intersubjectivity is not a problem of constitution which can be solved within the transcendental sphere, but rather a datum (Gegebenheit) of the life-world." This datum includes the fact that the social world is accepted as a world "for everyone," and this fact requires no explanation (Schutz, 1966: 83). The social world can be approached, however, through a descriptive phenomenological psychology (Schutz, 1962: 132), and it is to this task that Schutz turns in The Phenomenology of the Social World.

It is true that in Chapter 3 of that work, after analyses of conscious life under phenomenological reduction, Schutz (1967: 97, 1974: 137) abandons the strictly phenomenological method (especially the transcendental phenomenological reduction) to accept the existence of the social world as 
it is always accepted in the natural attitude, whether in everyday life or in sociological investigation. He thereby bypasses all the problems of constitution that arise within the transcendental-phenomenological viewpoint and that are not the concern of an analysis of the phenomenon of meaning in ordinary social life (Schutz, 1967: 44, 97, 1974: 56, 137). At the same time, however, in the important "Appended Note" at the end of his first chapter in The Phenomenology of the Social World - a note that Renn does not discuss in depth - Schutz (1967: 44; 1974: 56) insists that his whole work remains a piece of phenomenology, that is, a phenomenological psychology, remaining "on the ground of inner appearance as the appearance of that which is peculiar to the psychic." The Phenomenology of the Social World is also phenomenological insofar as it pursues an eidetic account of a society of mental (geistigen) life. On the basis of this somewhat maverick methodology, whose parameters Husserl (1952, 1981) himself sketched in his "Nachwort zu meinen Ideen," one would have to conclude that Schutz begins with the social world as it is accepted in everyday life but concentrates on the structural features of that world and especially on how actors experience those structures.

Given Schutz's methodology, one would be mistaken if one simply conceived of Schutz as loosely fusing together phenomenology and pragmatism, for that would be to neglect the phenomenological framework governing his entire investigation. Likewise, one ought to distinguish the experience of transcendental ego conceived within the welldefined constraints of the second epoche from that of the ego of the natural attitude, described by a phenomenological psychology that no longer observes the limits of strict phenomenological reduction. The former undertakes, unsuccessfully in the view of Schutz (1966: 57-67), a process aimed at constituting the other by abstracting from "everything that refers to other minds" and by transferring to the other the sense "another's living body." In the latter case, however, it is a matter of describing how actors already situated within the social world experience it. It is somewhat ironic in this regard that Schutz, who criticized Husserl's attempt at constitution of the other for creating a solispsism from which it cannot escape, should be criticized for inevitably shutting consciousness up within itself merely by relying upon phenomenology at all. Finally, one needs to be aware of the limits of Schutz's own project before asking that the project perform certain tasks that might well be beyond its own self-defined scope.

Let us then turn, though, to specific objections. Renn is correct to note that Schutz (1967: 103, 1974: 144) clearly distinguishes the inner time of human consciousness, which in communication is synchronized with the inner time of another consciousness, from outer time, that is, the time in 
which a thing in the outer world - a thing that could be lacking any durée of its own - would persist. But this difference, which Schutz never describes as "radical," does not imply that objective time is so swallowed up by the ego's subjective time that it requires some kind of criterion to establish that ego's objective time correlates with alter's. Objective time in the natural attitude by definition is common to all of us, is measurable by clocks and calendars, and makes intersubjective coordination of individual plan systems possible (Schutz, 1962: 222). Any account that would have as a result the denial of objective time would contradict a substantial feature of the natural attitude, but Schutz, insofar as he is still engaging in phenomenology, further explains how commonsense actors experience that objective time.

Such experience occurs (Schutz, 1962: 215) when one apprehends one's own bodily movements simultaneously on two planes: as givens in inner time but also as movements in the outer world, that is, as events happening in space and in spatial, objective time; and, of course, the other's body would be experienced as part of that objective setting. Furthermore, via the general thesis of the reciprocity of perspectives, commonsense thinking in the daily life of the natural attitude comes to terms with this outer world and its common time. This thesis involves an "idealization" that calls for no cognitive deduction or deliberation, but rather functions as a habitually, automatically assumed and executed way of intending objects. By deploying this idealization, commonsense actors already situated in the objective world and yet aware of their differences in spatial location and relevances, overcome these differences in order to arrive at knowledge that is objective and anonymous, detached from one's own and others' definitions of the situation, biographical circumstances, and purposes at hand (Schutz, 1962: 11-12). Through this idealization, each of us grasps directly, "as everyone's knowledge," "objects and their aspects," that is, all that pertains to the objective domain, including objective time (Schutz, 1962: 11-12).

Renn (2006: 6) considers this idealization as Schutz's warrant that the transcendental analysis of subjective constitution holds true for mundane subjective orientation. This way of considering the idealization, however, conceives it as device by which Schutz is able to implant a detached transcendental ego within mundane experience. Schutz (1962: 11-12), though, simply describes the idealization as a mechanism utilized by commonsense actors, who, already taking for granted a common world, overcome differences in individual perspectives of which they are also aware. Furthermore, Renn's tying the thesis of the reciprocity of perspectives to transcendental analysis obscures the fact that Schutz's descriptions of the idealization proceed on a level at which commonsense 
actors are already in direct contact with objective things through an intentionality in no way cut off from them. By contrast, Renn's argument seems to presuppose that, if something is given to intentionality at all, the correlates of that intentionality would be dissociated from its environs. It is as if Renn believes that phenomenology itself basically consists in what Schutz took to be impossible in the second epoché, namely that one cut oneself off from "everything that refers to other minds" (Schutz, 1966: 57). Even Husserl (1960: 91-92) himself adopted this second epoché as a reflective stance toward a world already experienced as intersubjective for the purposes of explaining the intentionality in which "the being of others for me becomes 'made' and explicated in respect of its rightful content."

Besides, the fact that for Schutz the body is experienced not only in outer time, but also in inner time, that is, as pertaining to one's stream of consciousness, gives no grounds to conclude that inner time is so separated (and certainly not "radically" separated) from objective time that one would be denied access to it (or to the entire objective sphere). These two times are coordinated for Schutz (1962: 215-216) insofar as "In simultaneity we experience the working action as a series of events in outer and in inner time, unifying both dimensions into a single flux which shall be called the vivid present," at the "intersection of durée and cosmic time." As a description of how we experience our bodies and time in everyday life, this account seems adequate; and, as a result, it is difficult to understand why the synchronization of ego's and alter's inner times should lead to any question as to whether ego's identification of outer time can be identified with alter's identification of it. The only way to pose this question would be if one supposed that ego's grasp of objective time (and the body which is the bridge to it) would be confined within ego's own stream of consciousness and that the intentionality of ego - and for that matter alter ego - could never reach beyond itself or achieve direct contact with a common domain. But in his "Appended Note," Schutz (1967: 43-44, 1974: 55-56) had already retracted the methodological limitations that might have led to such a predicament and dedicated himself instead to describing how one experiences the social world to which one belongs prior to phenomenological reflection.

In the second problem of synchronization, the access problem, Renn (2006: 8) detects inconsistency insofar as Schutz insists that the nonreflective, better access of ego to alter's stream of consciousness seems to provide "certainty" about alter's stream, contradictory to Schutz's repeated assertion that ego's understanding of alter is only a matter of ego's understanding. The first point to notice, though, is that Schutz (1967: 102, 1974: 143), in the opening of section 20 of The Phenomenology of the Social World that Renn cites, never characterizes ego's immediate 
grasp of what alter will have access to only reflectively as being "certain." In fact, Schutz immediately proceeds to comment on how the advantages of that immediate grasp of alter's present are offset by ego's lack of access to the fullness, past and future, of alter's stream. Ego captures only disconnected segments of alter's stream, arranged within ego's meaning-context; and Schutz (1967: 104-107, 1974: 145-148) admits that, though ego could keep track of alter's experiences in their continuity (Kontinuität), it does not grasp them in the completeness of their content (Vollständigkeit seiner Inhalte) and always falls short of grasping their totality. But interestingly, after introducing these difficulties in understanding the other, Schutz does not conclude that there is a "rigid difference" between ego's understanding of alter and alter's self-understanding (Renn, 2006: 8). Rather, Schutz (1967: 107, 1974: 148) makes the more qualified claims that knowledge of other people's consciousness is "always in principle open to doubt" and that what can be comprehended is always only an "approximate value" of the limiting concept, "the other's intended meaning." This fallibilism about knowing the other need not be contradictory if Schutz never claimed "certainty" for such knowledge in the first place, and it need not imply that there is no knowledge of the other. Rather it is a matter of different ways and aspects in which ego has advantages and disadvantages when it comes to understanding the other. In fact, repeatedly throughout his corpus, at moments when he mentions just some of the obstacles that Renn documents and that might lead to a denial that ego could ever understand alter's experience, Schutz (1962, 56, 322-323; 1967: 99, 124-125, 129, 1974: 140, 173-174, 181) does not hesitate to affirm that, for ego, alter's experiences are not in principle inaccessible or meaningless, but that ego does not give precisely the same meaning to alter's experiences as alter does. Moreover, though there are insurmountable limits for a fully successful communication in the ideal sense, "communication is highly successful for many good and useful purposes" (Schutz, 1962: 323). Just as Renn stressed the "radical" gap between inner and outer time to deconstruct growing older together, so in the question of access he attributes to Schutz a claim for "certainty" of understanding that is belied by the limits of mutual understanding, exaggerated at times to the point that the "rigid difference" between ego and alter all but seems to imply that ego will be ever self-contained when it comes to understanding alter. In each case, though, Schutz is more modulated in his language and highlights the nuances of the distinctions he develops - nuances that prevent those distinctions from polarizing into dualisms.

Renn's third objection has to do with how Schutz's discussion of appresentation, that is, the coordination between signs and objects, ends 
up reverting to a monological notion of sense constitution with only three relata: sign, meaning, and subject. It is correct that Schutz's initial presentation (1962: 294-300) of appresentation, in Section 2 of "Symbol, Reality, and Society," focuses on the relation between sign and meaning and thereby omits reference to any intersubjective relation between alter and ego and thus seems to lapse into an egological theory of meaning. However, Schutz (1962: 312) specifically admits in Section 4 of the same essay that he had refrained for methodological purposes from referring to these intersubjective dimensions. He then includes them and treats in detail the kinds of limits to understanding the other that appear in conjunction with the above discussion of the access problem of synchronization.

Furthermore, Renn (2006: 10) suggests that Schutz presupposes the intersubjectivity of pregiven symbolic structures to solve the problem of access to the other - a more fruitful strategy according to the pragmatic outlook. Such symbolic structures are indeed pregiven insofar as Schutz is describing the social world within which actors are already situated, but Schutz does not take these structures to solve the problem of access, since within the social world actors do not experience the problem of access that a philosophical outlook doing more than describing might be willing to import into everyday life. In fact, Schutz (1964: 232), the philosopher, adopts the task of simply describing how such structures are given to conscious experience; but to describe these conscious experiences to which such structures are given is not to imply that the contents experienced pertain only to the individual actor. As constituents of the objective domain, the symbolic structures would be taken through the reciprocity of perspectives as pertaining to a common world, superseding each individual's private experience, and providing thereby the kind of intersubjective coordination that the pragmatists desire. Of course, one might attempt to pull this experience of the common world back into the consciousness of the individual subject, claiming that it is only an individual's experience of the world being common and not necessarily a common world. Such a move, though, seems predicated on the idea that because an experienced content must be correlative to an individual's act of experiencing that content itself cannot be common. This supposition seems at odds with much of the phenomenological tradition, beginning, for example, with the idea of Husserl (1900-1901/2001, vol. 2: 292-294) that there could be categorial intuitions of universals.

It is worth noting, however, that a central insight pervading Schutz's work, which highlights how symbolic structures are taken with reference to conscious experience, has to do with how mundane, taken for granted, objective meanings, such as words (for example, the word "demonic" in 
Goethe), roles (e.g., mother and business person), and policies (e.g., equality of opportunity) are always suffused with an accompanying subjective meaning according to the subjective point of view of whoever makes use of them (Schutz, 1964: 254, 269-273, 1967: 124, 1974: 174). It is precisely this insight that could have been lost had Schutz abandoned his maverick methodology and thrown his methodological lot in completely with the pragmatist strategy focused only on presupposed intersubjective symbol systems.

During this discussion of Schutz's symbolism essay, Renn (2006: 9) charges Schutz with being inconsistent for embracing an appresentation account of the alter ego, an account criticized in a different later context. In this obvious reference to Schutz's 1957 essay on transcendental intersubjectivity in Husserl - written 2 years after the symbolism essay - Renn neglects to point out how Schutz (1966: 63) in that later essay, acknowledges the earlier essay and reasserts the importance of appresentation for establishing the nexuses between sign and signatum and between symbol and what is symbolized. It is true that in the course of the earlier symbolism essay Schutz (1962: 313-315) had mentioned how the other's material body in commonsense does in a general way appresent or indicate (semi-symbolically) the experiences of the other. However, Schutz's dispute with the "Fifth Cartesian Meditation" in the intersubjectivity essay focuses on a particular stage of Husserl's argument, having to do with his use of "the theory of appresentation to supply the foundation for the analogical appreciation of a body appearing in my primordially reduced sphere as an 'other living body" (Schutz, 1966: 63). While one might be willing to allow common sense actors to make generalized use of the concept of appresentation insofar as they take the other's body to appresent in a semi-symbolic way his or her conscious experiences, one ought not grant the same liberty to Husserl in the context of a carefully constructed philosophical argument which for Schutz (1966: 62-64) stumbles when Husserl appresentatively transfers the sense "living body" to another despite his earlier insistence on the unique manner that one's own body is given to oneself.

When Renn (2006: 10-11) criticizes Schutz for not treating somewhere the question of intersubjective sense constitution, the problem of social order, the conditions of the internalization of meaning, and the processes through which the social constitution of the sense-constituting subject takes place, he does point to areas in need of philosophical development. However, these topics lie beyond the limits of Schutz's own project self-defined as a phenomenology of the natural attitude. Moreover, while Schutz lacks a fully developed concept of "genuine interactive symbolic generalization" that might envision cooperation 
leading to context-transcending symbolization, his discussion in "Making Music Together" (1964: 177) of jazz players improvising in a jam session, cooperating together to produce melodies never heard before, suggests that his thought could have been taken in just such a direction. In addition, Schutz's talk (1964: 91-105) in his essay "The Stranger" on "cultural patterns" and "recipes of action," for instance, does seem to conceive typifications not as the representation of intentional objects or cognitive concepts one has in mind, but rather as performative rules for acting and speaking.

\section{A Future Rapprochement?}

Up to this point, my criticism has been that Renn misunderstands Schutz's views, overlooks their complexity, and criticizes him for not delivering what he never promised. My problem then has to do with his interpretation of Schutz. By contrast, I find myself in agreement with most of Renn's comments in the final sections of his paper in which he suggests that other philosophical methodologies are necessary for a comprehensive understanding of the social world and that Schutz's work could play a complementary role in relation to these other methodologies. Schutz's position, though, would not only protect subjective freedom against objectivism and preserve a sensitivity in concrete encounters with particular meaning aspects in contextual circumstances, as Renn (2006: 15-16) rightly observes. In addition, all the difficulties in understanding between ego and alter upon which Renn based much of his earlier critique have to do with the fundamental differences between individuals and the otherness of others to oneself and oneself to them - factors not be lost of sight in any communicative process. Although Renn (2006: 16, 13) claims that Schutz understood the "looking glass effect" to involve a rigid intrusion of social convention into the interpreting subject and a mere reduplication of the social order, one could also see it as basic for "the communicative constitution of the mundane ego" that Renn (2006: 15) calls for. What would be involved would be an interlocking of intentionalities in mutual recognition, as described by Hegel (1807), Habermas (1992), and most recently Robert Brandom. When Brandom (2002: 217) insists that selves are normative structures instituted by reciprocal recognition, I can easily imagine, in Schutzian terms, someone interpreting me interpreting her or him as worthy of recognition and thereby confirming her or his identity as that of one deserving dignified treatment and accountable for treating others with dignity. ${ }^{1}$ And I can imagine her or him doing the same for me. The added benefit of course, would be that, from a Schutzian standpoint 
and in line with Renn's own final observations (2006: 15-16), the other's and my difference and uniqueness, underpinned by our historically unfolding consciousnesses, would also always be at the table where identity-shaping normative accords are reached.

\section{Note}

1. Brandom (1994: 139, 641, 646-647) is aware that perspectivism is involved in any discursive situation between scorekeepers and that all the deontic attitudes, background conditions, and practical inferential know-how involved in scorekeeping cannot be made explicit at once, though nothing is immune from being made explicit. How the phenomenological tradition with its emphasis on historical consciousness affecting affective and cognitive dimensions could complement Brandom's recognitions of linguistic and discursive differences points in the direction of further philosophical work.

\section{References}

Brandom, R. (1994). Making It Explicit: Reasoning, Representing, and Discursive Commitment. Cambridge and London: Harvard University Press.

Brandom, R. (2002). Tales of the Mighty Dead: Historical Essays in the Metaphysics of Intentionality. Cambridge and London: Harvard University Press.

Habermas, J. (1988). On the Logic of the Social Sciences. Trans. S.W. Nicholsen and J.A. Stark. Cambridge: MIT Press.

Habermas, J. (1992). Postmetaphysical Thinking. Trans. W.M. Hohengarten. Cambridge: MIT Press.

Hegel, G.W.F. (1807/1977). The Phenomenology of Spirit. Trans. A.V. Miller. Oxford: Clarendon Press.

Husserl, E. (1931/1960). Cartesian Meditations: An Introduction to Phenomenology. Trans. Dorion Cairns. The Hague: Martinus Nijhoff.

Husserl, E. (1900-1901/2001). Logical Investigations, 2 volumes. Trans. J.N. Findlay. London and New York: Routledge.

Husserl, E. (1958). Nachwort. In Ideen zu einer reinen Phänomenologie und phänomenologische Philosophie, Book 3: Die Phänomenologie und die Fundamente der Wissenschaften. Ed. M. Biemel. The Hague: Martinus Nijhoff.

Husserl, E. (1981). Author's Preface to the English Edition of Ideas. Trans. W.R. B.Gibson. In Husserl: Shorter Works. Eds. McCormick, P. and Elliston, F. Notre Dame: University of Notre Dame Press.

Renn, J. (2006). Appresentation and Simultaneity: Alfred Schutz on Communication between Phenomenology and Pragmatics. Human Studies 29(1): 1-19.

Schutz, A. (1932/1974). Der sinnhafte Aufbau der sozialen Welt: Eine Einleitung in die verstehende Soziologie. Frankfurt am Main: Suhrkamp. English translation (1967): The Phenomenology of the Social World. Trans. G. Walsh and F. Lehnert. Evanston: Northwestern University Press.

Schutz, A. (1962). The Problem of Social Reality (Collected Papers, vol. 1). Ed. M. Natanson. The Hague: Martinus Nijhoff. 
Schutz, A. (1964). Studies in Social Theory (Collected Papers, vol. 2). Ed. A. Brodersen. The Hague: Martinus Nijhoff.

Schutz, A. (1966). Studies in Phenomenological Philosophy (Collected Papers, vol. 3). Ed.

I. Schutz. The Hague: Martinus Nijhoff.

Welz, F. (1996). Kritik der Lebenswelt: Eine soziologische Auseinandersetzung mit Edmund Husserl und Alfred Schütz. Opladen: Westdeutscher Verlag GmbH. 